\title{
Necroptosis in primate luteolysis: a role for ceramide
}

Konstantin Bagnjuk', Jan Bernd Stöckl ${ }^{2}$, Thomas Fröhlich², Georg Josef Arnold ${ }^{2}$, Rüdiger Behr $\mathbb{D}^{3}$, Ulrike Berg ${ }^{4}$, Dieter Berg ${ }^{4}$, Lars Kunz $\mathbb{0}^{5}$, Cecily Bishop ${ }^{6}$, Jing Xu ${ }^{6}$ and Artur Mayerhofer ${ }^{1}$

\begin{abstract}
The corpus luteum $(\mathrm{CL})$ is a transient endocrine organ, yet molecular mechanisms resulting in its demise are not well known. The presence of phosphorylated mixed lineage kinase domain-like pseudokinase pMLKL(T357/S358) in human and nonhuman primate CL samples (Macaca mulatta and Callithrix jacchus) implied that necroptosis of luteal cells may be involved. In M. mulatta CL, pMLKL positive staining became detectable only from the mid-late luteal phase onwards, pointing to necroptosis during regression of the $\mathrm{CL}$. Cell death, including necroptosis, was previously observed in cultures of human luteal granulosa cells (GCs), an apt model for the study of the human CL. To explore mechanisms of necroptotic cell death in GCs during culture, we performed a proteomic analysis. The levels of 50 proteins were significantly altered after 5 days of culture. Interconnectivity analysis and immunocytochemistry implicated specifically the ceramide salvage pathway to be enhanced. M. mulatta CL transcriptome analysis indicated in vivo relevance. Perturbing endogenous ceramide generation by fumonisin B1 (FB1) and addition of soluble ceramide (C2-CER) yielded opposite actions on viability of GCs and therefore supported the significance of the ceramide pathway. Morphological changes indicated necrotic cell death in the C2-CER treated group. Studies with the pan caspase blocker zVAD-fmk or the necroptosis blocker necrosulfonamid (NSA) further supported that C2-CER induced necroptosis. Our data pinpoint necroptosis in a physiological process, namely $C L$ regression. This raises the possibility that the primate $\mathrm{CL}$ could be rescued by pharmacological inhibition of necroptosis or by interaction with ceramide metabolism.
\end{abstract}

\section{Introduction}

The corpus luteum (CL) forms after ovulation. Upon the ovulatoryluteinizing hormone (LH) surge granulosa and theca cells differentiate into large and small luteal cells, stop dividing and produce progesterone $\mathrm{e}^{1,2}$. If conception occurs, chorionic gonadotropin (CG) stimulates survival of the CL and progesterone production. Otherwise the CL shuts down functionally and degenerates structurally.

\footnotetext{
Correspondence: Artur Mayerhofer (Mayerhofer@lrz.uni-muenchen.de) ${ }^{1}$ Biomedical Center Munich (BMC), Cell Biology, Anatomy III, LudwigMaximilians-University (LMU), Grosshaderner Strasse 9, Planegg 82152, Germany

${ }^{2}$ Laboratory for Functional Genome Analysis LAFUGA, Gene Center, LMU, Feodor-Lynen Strasse 25, Munich 81375, Germany

Full list of author information is available at the end of the article. Edited by N. Barlev
}

Knowledge about the molecular events leading to functional and structural regression of the primate CL is limited. Low accessibility and significant differences in luteolytic events between primates and non-primate species may explain this lack of knowledge ${ }^{3}$. A fraction of the luteal cells undergo apoptosis in humans ${ }^{4,5}$, and involvement of autophagocytosis was suggested ${ }^{6-8}$. Both are immunologically silent events, yet other forms of cell death attract immune cells. Immune cells, for example, macrophages, appear to play an indispensable role in ovarian functions ${ }^{9}$ and $\mathrm{CD} 11 \mathrm{~b}$ positive macrophages invade the nonhuman primate $\mathrm{CL}$ during its regression and produce various cytokines and chemokines ${ }^{10}$.

Immune cell accumulation in the CL may be a consequence of necroptosis, a process recently suggested to occur in the regressing CL of cows ${ }^{11}$. Necroptosis is a

\section{(c) The Author(s) 2019}

(c) Open Access This article is licensed under a Creative Commons Attribution 4.0 International License, which permits use, sharing, adaptation, distribution and reproduction cc) in any medium or format, as long as you give appropriate credit to the original author(s) and the source, provide a link to the Creative Commons license, and indicate if changes were made. The images or other third party material in this article are included in the article's Creative Commons license, unless indicated otherwise in a credit line to the material. If material is not included in the article's Creative Commons license and your intended use is not permitted by statutory regulation or exceeds the permitted use, you will need to obtain permission directly from the copyright holder. To view a copy of this license, visit http://creativecommons.org/licenses/by/4.0/. 
combination of events, which include phosphorylation of receptor interacting protein kinase 1 (RIP1) and 3 (RIP3), formation of the necrosome, as well as phosphorylation of mixed lineage kinase domain-like pseudokinase (MLKL, at T357/S358) and its oligomerization to multimers including octamers $^{12,13}$. Execution of necroptosis is associated with the typical morphological signs of necrosis ${ }^{14}$.

Fluidity of the cell membrane and lipid composition change during $\mathrm{CL}$ regression, and changes in sphingomyelin levels in combination with cholesterol levels are implicated in the loss of CL function ${ }^{15}$. It was shown that activation of the sphingomyelin pathway by Fas cell surface death receptor ligand (FASLG) and consequently production of ceramide led to cell death in bovine luteal cells ${ }^{16}$.

Sphingolipid metabolism is complex. Three distinct pathways of ceramide synthesis are known. First, the sphingomyelin degradation pathway leads to generation of ceramide by acid and neutral sphingomyelinases. This pathway is induced by FASLG, TNF $\alpha$ and oxidative stress $^{17,18}$. Additionally, sphingolipids, especially ceramides, can be produced via de novo synthesis starting from serine and palmitoyl-CoA involving a cascaded reaction of 3-ketodihydrosphingosine reductase, dihydroceramide synthase and dihydroceramide desaturase in the endoplasmic reticulum ${ }^{19}$. Possible inducers of this pathway are heat stress, cannabinoids, chemotherapeutic agents and oxidized low density lipoprotein ${ }^{20}$. The third pathway is the ceramide salvage pathway. In late endosomes and lysosomes, sphingomyelin and complex sphingolipids are broken down to ceramide and sphingosine $^{21,22}$. Sphingosine can then be reused to generate ceramide, which gives this pathway its name. Key enzymes of this pathway are acid sphingomyelinase (SMPD1), acid ceramidase (ASAH1) and acid $\beta$-glucosidase (GBA1). This pathway has a strong impact on intracellular signalling and has been linked to apoptosis in other cellular systems $^{23}$. Recently, ceramide generation or its administration has also been linked to necroptosis ${ }^{24,25}$.

Human GCs are a unique model for the human CL. GCs stem from patients undergoing IVF and luteinize in culture. Investigations using this model led to the discovery of necroptosis in human GCs, in addition to apoptosis ${ }^{26}$. Inhibitors of MLKL (necrosulfonamid, NSA) and RIP1 (necrostatin-1, Nec-1) blocked necroptotic cell death. Evidence for in vivo relevance of this observation was obtained in ovarian sections of the rhesus macaque (Macaca mulatta) and the human, containing both follicles and the $\mathrm{CL}^{26,27}$. Strongest staining for pMLKL(T357/ S358) was, however, found in CL samples.

Based on these observations we hypothesized that necroptosis is involved in primate luteolysis. To examine molecular mechanisms, we studied timed primate ovarian tissue, employed human IVF-derived GCs as a cellular model, and performed mass spectrometry and transcriptomic analysis. The results support that necroptosis occurs during luteolysis in primates, and pinpoint ceramide and the ceramide salvage pathway.

\section{Results \\ Necroptosis occurs in the human and nonhuman primate $\mathrm{CL}$}

Immunohistochemical staining using anti-pMLKL(T357/ S358) antibody provided evidence for necroptotic pathway activation in luteal cells of human and nonhuman primates (marmoset and macaque; Fig. 1). The immunoreactive cells were large luteal cells (Fig. 2). Preabsorption controls (Fig. 1e-g) were negative. CL samples from different stages were studied in macaques. While 3- and 7-day-old CL samples were negative for pMLKL(T357/S358) (Fig. 1a, b), cells positive for $\mathrm{pMLKL}(\mathrm{T} 357 / \mathrm{S} 358)$ were evident in the 14 day-old CL (Fig. 1c).

\section{IVF-derived human GCs - a model for the human CL}

IVF-derived human GCs luteinize and are considered a model for luteinized GCs of the CL (Fig. 2) ${ }^{26}$. We attempted to validate this model by using a proteome analysis of GCs cultured for 2 to 5 days. LC-MS/MS data from cultured GCs and literature data of human CL and in vivo-developed primate luteal cells stemming from the mid to late luteal phase were compared. The results indicated a high level of similarity. For example, the cholesterol side-chain cleavage enzyme (CYP11A1), a known luteal-cell marker, was highly expressed (24th most abundant of 3642 detected proteins) in cultured $\mathrm{GCs}^{3}$. Progesterone (P4) synthesis in the CL mainly requires three proteins next to CYP11A1, low density lipoprotein receptor (LDL-R), 3 $\beta$-hydroxysteroid dehydrogenase $(3 \beta-\mathrm{HSD})$ and steroidogenic acute regulatory protein $(\mathrm{StAR})^{44}$. All of these proteins were expressed in GC samples.

\section{Human granulosa cells undergo necroptosis during culture}

To examine necrotic events, we analysed LDH levels in medium. After medium change at day 2 , we found a relative cytotoxicity of around $20 \%(n=8$, Fig. 3a) in cells cultured until day 3 (i.e. 1 day of $\mathrm{LDH}$ accumulation), if compared to maximally possible LDH. LDH levels were rising over culture time (Fig. 3a). After 3 consecutive days of LDH accumulation, we found a significant difference compared to the samples analysed on day $3(" p<0.05)$.

We next studied proteins known to become phosphorylated during necroptosis (RIP1, RIP3, MLKL). Unphosphorylated forms of those were found at all timepoint during culture (Fig. $3 \mathrm{~b}-\mathrm{d}$ ). In the beginning of necroptosis RIP1 is phosphorylated. Using anti-pRIP1(S166), we found the specific band, which was stronger on day 1 and 3 of culture if compared to day 5 (Fig. 3b). After RIP1 phosphorylation, RIP3 is recruited and phosphorylated at S227. 


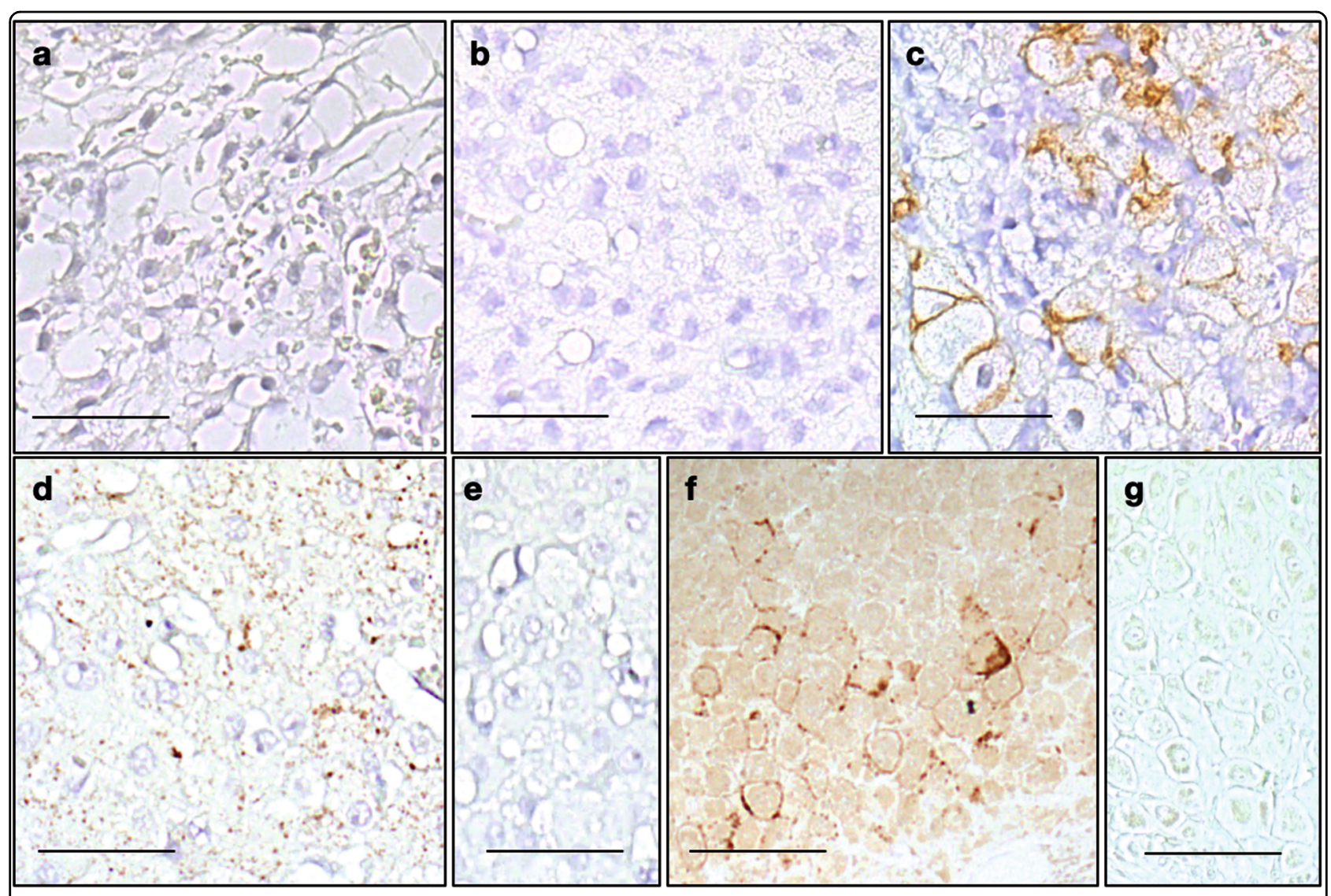

Fig. 1 Immunohistochemical staining of pMLKL(T357/S358) in human and nonhuman primate corpus luteum. Immunohistochemical staining of pMLKL(T357/S358) in CL from different species. The upper panels depict macaque CL in early-luteal (3 day old, a) and mid-luteal phase (7 day old, b) as well as during regression (14 days old, c). Lower panels show pMLKL(T357/S358) staining of large luteal cells in sections of human (d) and marmoset (f) CL. Corresponding pre-absorption controls are shown (e, g). Scale bars: 50 um. Representative images are shown

An antibody against this phosphorylated peptide revealed a faint band at $62 \mathrm{kDa}$ (Fig. 3c). Evaluation of band intensity showed a slight trend to more RIP3 being phosphorylated at late culture timepoints if compared to day 1 . Finally, MLKL is recruited to form the necrosome and oligomerized pMLKL is the executor of necroptosis. Western blots with anti-pMLKL(T357/S358) showed stronger bands at day 3 of cultivation if compared to day 1 (Fig. 3d). Additionally, the oligomerized form was only detectable at day 3 onwards, indicating execution of necroptosis at these timepoints. The specificity of the anti-pMLKL(T357/S358) antibody was tested $^{27}$. Taken together, the data indicate a trend of enhanced execution of necroptosis during culture time.

\section{Proteins associated with the ceramide salvage pathway} were highly upregulated in GCs over culture period, as well as during in vivo-development of the $\mathrm{CL}$

For GC samples from culture day 2 to 5, LC-MS/MS based proteomic analyses ( $n=5$ per day) were performed and a total of 3642 proteins were identified.

Quantified proteins were prefiltered, based on $p$ value and $\log _{2}$ fold change, and underwent a DAVID analysis to identify functional annotation clusters, which were enriched in day 5 compared to day 2 . Three clusters were found (Table 1). The first cluster contained 7 proteins involved in cholesterol biosynthesis, which all showed lower abundancy at day 5 . The second cluster included mainly translation initiation factors and translation associated proteins, which showed mostly small changes in abundancy. The third cluster contained 17 proteins, which were lysosome associated proteins. Most of these proteins are directly involved in the lysosomal ceramide salvage pathway and showed different degrees of raised abundance at day 5 ranging from $\log _{2}$ fold change 0.91 (HEXB) to 2.75 (GAA). An overview of the core pathway proteins and corresponding reactions is provided (Fig. 4a). For a detailed pathway see Supplementary Figure 1.

Transcriptomic data of in vivo-developed macaque CL showed that 8 of 14 genes associated with the ceramide salvage pathway were significantly upregulated in the late stage CL relative to the early stage $C L$ in macaques with $\log _{2}$ fold change ranging from 0.34 for arylsulfatase A (ARSA) to 1.51 for GM2 ganglioside activator (GM2A). ASAH1, GM2A, HEXA, HEXB, PSAP and SCARB2 were 


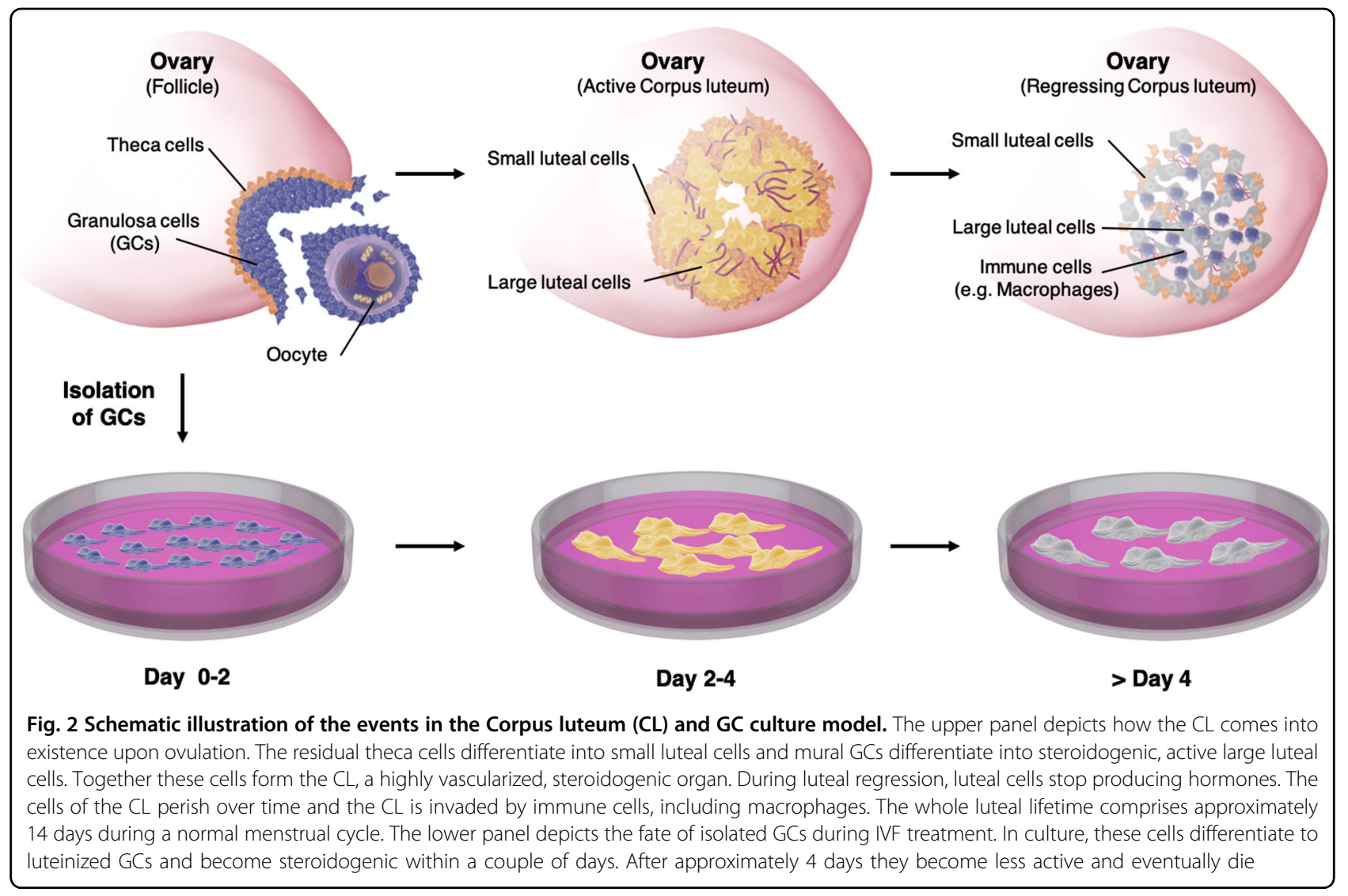

elevated in both the proteomics and the transcriptomics analysis (Supplementary Fig. 2, Supplementary Table 1). Validations employing real-time PCR revealed that the mRNA levels of ASAH1, SMPD1, GBA and CERS2 were likewise changed compared to the microarray data (data not shown).

The proteomics data were also filtered for q-values < 0.05 to identify highly significant differential abundance of proteins. The resulting 50 proteins were highlighted in a volcano plot (Fig. 4b). Several proteins were already found to be differentially abundant based on the DAVID enrichment analysis above, especially the lysosomal proteins. Granulins (GRN) were reported to have lysosomal activity and cytokine-like functions and were shown to be trafficked by prosaposin (PSAP) to the lysosome ${ }^{45}$. Both, GRN and PSAP were found to be highly abundant in cultured GCs on day 5 . The high $\log _{2}$ fold change $(-4.20)$ of the cytosolic hydroxymethylglutaryl-CoA synthase (HMGCS1) and the reduction of another protein associated with cholesterol synthesis, namely vigilin (also known as high density lipoprotein-binding protein, HDLBP, $\log _{2}$ fold change (-1.08)), became evident. The RNA binding protein vigilin is reported to protect cells from overaccumulation of cholesterol ${ }^{46}$. Collectively, these data point to the ceramide salvage pathway, and accumulation of its metabolic products ceramide and sphingosine, involved in cell death of in vitro cultured GCs and in vivo-developed CL.

\section{Cell studies using FB1 support a role of the ceramide pathway in GCs viability}

The LC-MS/MS data in combination with the transcriptomic data in a nonhuman primate indicated an accumulation of ceramide or sphingosine in cultured GCs and in the regressing CL (Supplementary Fig. 2 and Supplementary Table 1). To further examine this possibility in vitro, immunocytochemical staining of ceramide species and the Golgi apparatus were carried out ${ }^{35}$. GCs at day 2 and day 5 of culture, as well as after $72 \mathrm{~h}$ of treatment with the known ceramide synthase blocker fumonisin B1 (FB1, $0.5 \mu \mathrm{M})$ were studied. At day 2, the ceramide staining was mainly localized to the Golgi apparatus, as shown by co-staining with anti-golgin97 (Fig. 4c). After 5 days of culture, cells had grown in size, which was indicated by the larger nuclei and Golgi apparatus. Ceramide staining intensity also increased. In addition to the Golgi apparatus, it was associated presumably with cell membranes of other cell compartments. As expected, FB1 treatment reduced ceramide staining intensity (Fig. 4c). These findings support the LC-MS/MS 


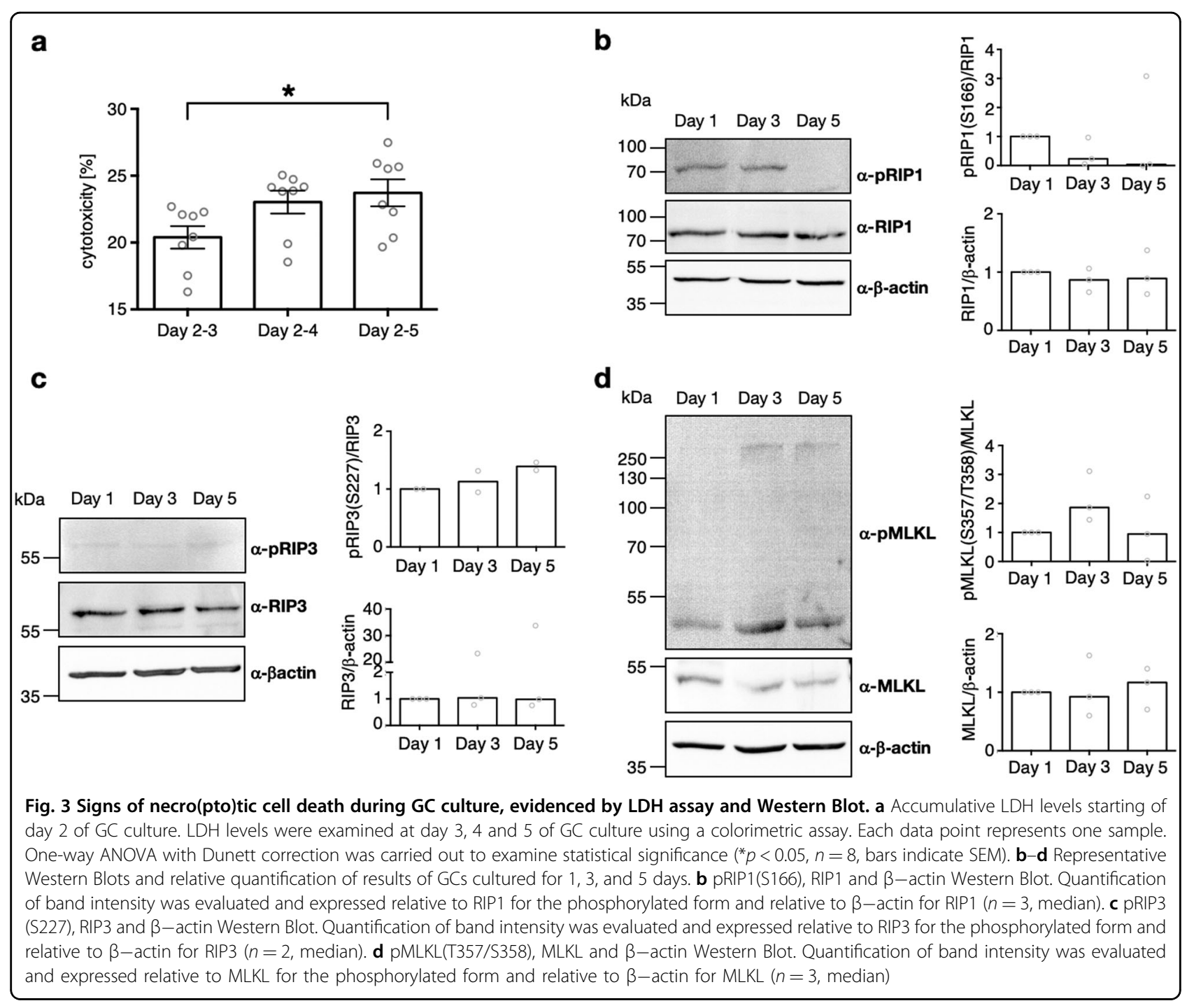

and transcriptomic data and show the significance of ceramide synthases in ceramide generation.

Next, we treated GCs with FB1 $(0.5 \mu \mathrm{M})$ at day 1 of culture and determined cell confluency over a time period of $72 \mathrm{~h}$ (Fig. 4d). FB1-treatment increased confluency by $17.6 \pm 11.1 \%$ ( $n=6$, Fig. $4 d$, right diagram) compared to the solvent control. Furthermore, FB1 treatment significantly increased cell number $\left(7.76 \times 10^{4} \pm 0.65 \times 10^{4}\right.$ cells, $n=11)$ compared to controls $\left(6.41 \times 10^{4} \pm 0.57 \times\right.$ $10^{4}$ cells, $n=11$, Fig. $4 \mathrm{~d}$, bar diagram). The data indicate that blocking ceramide synthases and therefore lowering ceramide levels has a positive effect on GC viability.

\section{A soluble ceramide analogue induced a form of necrotic cell death in human GCs}

Cell studies with FB1 showed that endogenously produced ceramide has a negative effect on GC viability. To further examine the significance of ceramide in GC culture, we added the soluble ceramide analogue $\mathrm{C} 2$ ceramide $(\mathrm{C} 2$-CER, $50 \mu \mathrm{M})$ at day 1 or 2 of culture and evaluated confluency, cell number (Fig. 5a), as well as medium LDH levels (Fig. 5b). In the C2-CER-treated group we found significantly reduced confluency after $72 \mathrm{~h}$ by $17.5 \pm 2.9 \%(n=9$, Fig. $5 \mathrm{a}$, x/y diagram $)$ compared to the solvent control group. This was accompanied by an augmentation of typical morphological signs of necro(pto) tic cell death, e.g., ballooning (Fig. 5a, images). Additionally, $72 \mathrm{~h}$ stimulation with C2-CER significantly reduced cell number to $4.64 \times 10^{4} \pm 0.65 \times 10^{4} \quad(n=11)$, compared to controls $\left(6.86 \times 10^{4} \pm 0.64 \times 10^{4}, n=11\right.$, Fig. 5a, bar diagram).

We measured accumulation of medium LDH after 24, 48 and $72 \mathrm{~h}$, starting of day 2 of culture. LDH levels and subsequently relative cytotoxicity between day 2-3 were not significantly altered due to C2-CER $(50 \mu \mathrm{M})$ stimulation (Fig. 5b, $n=8$, upper diagram). After 48 h (Fig. 5b, 
Table 1 DAVID clusters of proteome analysis

\begin{tabular}{|c|c|c|c|c|}
\hline Protein name & Gene name & Uniprot accession & $\begin{array}{l}\log _{2} \text { fold } \\
\text { change }\end{array}$ & $p$ value \\
\hline \multicolumn{5}{|l|}{ Cluster 1: cholesterol biosynthesis } \\
\hline 3-hydroxy-3-methylglutaryl-CoA synthase 1 & HMGCS1 & Q01581 & -4.20 & $1.8 \mathrm{E}-04$ \\
\hline 7-dehydrocholesterol reductase & DHCR7 & Q9UBM7 & -0.81 & $2.6 \mathrm{E}-02$ \\
\hline $\begin{array}{l}\text { SWI/SNF related, matrix associated, actin dependent regulator of chromatin, } \\
\text { subfamily } d \text {, member } 3\end{array}$ & SMARCD3 & Q6STE5 & -0.97 & $2.0 \mathrm{E}-02$ \\
\hline Acetyl-CoA carboxylase alpha & ACACA & Q13085 & -2.09 & $1.4 \mathrm{E}-02$ \\
\hline Cytochrome P450 family 51 subfamily A member 1 & CYP51A1 & Q16850 & -2.77 & $9.1 \mathrm{E}-03$ \\
\hline Farnesyl diphosphate synthase & FDPS & P14324 & -0.93 & $9.4 \mathrm{E}-04$ \\
\hline Isopenteny|-diphosphate delta isomerase 1 & IDI1 & Q13907 & -2.02 & $3.9 \mathrm{E}-02$ \\
\hline \multicolumn{5}{|l|}{ Cluster 2: translation initiation/ translation associated proteins } \\
\hline Eukaryotic translation initiation factor 3 subunit I & EIF3I & Q13347 & -0.70 & $9.3 \mathrm{E}-03$ \\
\hline Eukaryotic translation initiation factor 3 subunit J & EIF3J & O75822 & -0.70 & $1.8 \mathrm{E}-02$ \\
\hline Eukaryotic translation initiation factor 3 subunit $\mathrm{K}$ & EIF3K & Q9UBQ5 & -1.63 & $1.6 \mathrm{E}-02$ \\
\hline Eukaryotic translation initiation factor 3 subunit $L$ & EIF3L & Q9Y262 & -0.63 & $1.4 \mathrm{E}-02$ \\
\hline Eukaryotic translation initiation factor $4 \mathrm{~A} 1$ & EIF4A1 & P60842 & -0.64 & $5.5 \mathrm{E}-03$ \\
\hline Heat shock protein family B (small) member 1 & HSPB1 & P04792 & -1.19 & 2.7E-02 \\
\hline Ribosomal protein L22-like 1 & RPL22L1 & Q6P5R6 & -1.82 & $3.9 \mathrm{E}-03$ \\
\hline Ribosomal protein L24 & RPL24 & P83731 & -0.67 & $2.8 \mathrm{E}-02$ \\
\hline Ribosomal protein S14 & RPS14 & P62263 & -0.65 & $6.8 \mathrm{E}-03$ \\
\hline \multicolumn{5}{|l|}{ Cluster 3: lysosomal proteins } \\
\hline GM2 ganglioside activator & GM2A & P17900 & 1.39 & 1.7E-02 \\
\hline N-acetyl-alpha-glucosaminidase & NAGLU & P54802 & 1.80 & $9.4 \mathrm{E}-03$ \\
\hline $\mathrm{N}$-acylsphingosine amidohydrolase 1 & ASAH1 & Q13510 & 2.57 & $6.4 \mathrm{E}-03$ \\
\hline Arylsulfatase B & ARSB & P15848 & 2.43 & $3.4 \mathrm{E}-04$ \\
\hline Cathepsin A & CTSA & P10619 & 1.85 & 3.7E-06 \\
\hline Cathepsin D & CTSD & P07339 & 1.03 & $9.8 \mathrm{E}-04$ \\
\hline Fucosidase, alpha-L- 1, tissue & FUCA1 & P04066 & 1.58 & $3.4 \mathrm{E}-03$ \\
\hline Galactosylceramidase & GALC & P54803 & 1.81 & $4.3 \mathrm{E}-02$ \\
\hline Glucosamine (N-acetyl)-6-sulfatase & GNS & P15586 & 0.94 & 7.8E-04 \\
\hline Glucosidase alpha, acid & GAA & P10253 & 2.75 & $3.6 \mathrm{E}-02$ \\
\hline Hexosaminidase subunit alpha & HEXA & P06865 & 1.37 & $4.8 \mathrm{E}-04$ \\
\hline Hexosaminidase subunit beta & HEXB & P07686 & 0.91 & $2.9 \mathrm{E}-04$ \\
\hline Neuraminidase 1 & NEU1 & Q99519 & 2.12 & $3.2 \mathrm{E}-02$ \\
\hline Phospholipase B domain containing 2 & PLBD2 & Q8NHP8 & 1.04 & $2.9 \mathrm{E}-03$ \\
\hline Prosaposin & PSAP & P07602 & 1.06 & $2.2 \mathrm{E}-03$ \\
\hline Scavenger receptor class B member 2 & SCARB2 & Q14108 & 1.51 & 1.7E-02 \\
\hline Sphingomyelin phosphodiesterase 1 & SMPD1 & P17405 & 1.17 & $6.4 \mathrm{E}-03$ \\
\hline
\end{tabular}

Results of the DAVID annotation clustering. Three clusters were found to be enriched. Every cluster is shown with the corresponding proteins and the changes in abundancies 
Table 250 significantly differentially abundant proteins between day 2 and day 5 of GC culture

\begin{tabular}{|c|c|c|c|}
\hline Protein name & Gene name & $\log _{2} f c$ & $p$ value \\
\hline $\begin{array}{l}\text { Hydroxymethylglutaryl-CoA synthase, } \\
\text { cytoplasmic }\end{array}$ & HMGCS1 & -4.20 & $1.82 \mathrm{E}-04$ \\
\hline Fibrinogen beta chain & FGB & -4.09 & 5.47E-03 \\
\hline Fibrinogen alpha chain & FGA & -3.78 & 7.55E-03 \\
\hline $\begin{array}{l}\text { Signal recognition particle subunit } \\
\text { SRP72 }\end{array}$ & SRP72 & -3.67 & $1.13 \mathrm{E}-02$ \\
\hline Lanosterol 14-alpha demethylase & CYP51A1 & -2.77 & $9.09 \mathrm{E}-03$ \\
\hline Fatty acid desaturase 2 & FADS2 & -2.56 & $6.55 \mathrm{E}-06$ \\
\hline Nucleolar RNA helicase 2 & DDX21 & -2.32 & $1.95 \mathrm{E}-03$ \\
\hline Protein transport protein Sec23B & SEC23B & -2.26 & $1.75 \mathrm{E}-03$ \\
\hline RNA polymerase II-associated protein 3 & RPAP3 & -2.26 & $7.72 \mathrm{E}-03$ \\
\hline LIM and cysteine-rich domains protein 1 & LMCD1 & -2.12 & 2.76E-03 \\
\hline $60 \mathrm{~S}$ ribosomal protein L22-like 1 & RPL22L1 & -1.82 & $3.90 \mathrm{E}-03$ \\
\hline DnaJ homolog subfamily A member 1 & DNAJA1 & -1.78 & $9.18 \mathrm{E}-03$ \\
\hline $\begin{array}{l}\text { Arf-GAP domain and FG repeat- } \\
\text { containing protein } 1\end{array}$ & AGFG1 & -1.78 & $9.24 \mathrm{E}-03$ \\
\hline Zinc transporter ZIP14 & SLC39A14 & -1.73 & 2.05E-03 \\
\hline EH domain-containing protein 1 & EHD1 & -1.63 & $2.14 \mathrm{E}-03$ \\
\hline A-kinase anchor protein 2 & AKAP2 & -1.61 & $8.69 \mathrm{E}-03$ \\
\hline $\begin{array}{l}\text { Proteasome-associated protein } \\
\text { ECM29 homolog }\end{array}$ & ECM29 & -1.56 & $1.45 \mathrm{E}-03$ \\
\hline Serotransferrin & TF & -1.48 & $6.79 \mathrm{E}-03$ \\
\hline E3 ubiquitin-protein ligase UBR4 & UBR4 & -1.32 & $3.35 \mathrm{E}-03$ \\
\hline Coiled-coil domain-containing protein 47 & CCDC47 & -1.28 & $6.43 \mathrm{E}-03$ \\
\hline Plasminogen activator inhibitor 2 & SERPINB2 & -1.27 & 2.07E-03 \\
\hline Golgi membrane protein 1 & GOLM1 & -1.21 & $3.63 \mathrm{E}-03$ \\
\hline $\begin{array}{l}\text { Neuroblast differentiation-associated } \\
\text { protein AHNAK }\end{array}$ & AHNAK & -1.19 & 3.39E-04 \\
\hline $\begin{array}{l}\text { ATP-dependent Clp protease ATP- } \\
\text { binding subunit clpX-like, } \\
\text { mitochondrial }\end{array}$ & CLPX & -1.18 & $2.52 \mathrm{E}-03$ \\
\hline Vigilin & HDLBP & -1.08 & 2.81E-03 \\
\hline Histone deacetylase 6 & HDAC6 & -1.00 & $1.22 \mathrm{E}-04$ \\
\hline Farnesyl pyrophosphate synthase & FDPS & -0.93 & 9.37E-04 \\
\hline Beta-hexosaminidase subunit beta & HEXB & 0.91 & 2.88E-04 \\
\hline N-acetylglucosamine-6-sulfatase & GNS & 0.94 & 7.76E-04 \\
\hline Cathepsin D & CTSD & 1.03 & $9.81 \mathrm{E}-04$ \\
\hline Putative phospholipase B-like 2 & PLBD2 & 1.04 & 2.91E-03 \\
\hline Prosaposin & PSAP & 1.06 & 2.20E-03 \\
\hline Integrin alpha-1 & ITGA1 & 1.10 & $1.94 \mathrm{E}-03$ \\
\hline
\end{tabular}

Table 2 continued

\begin{tabular}{llll}
\hline Protein name & Gene name & $\log _{\mathbf{2}}$ fc & $\boldsymbol{p}$ value \\
\hline Sphingomyelin phosphodiesterase & SMPD1 & 1.17 & $6.37 \mathrm{E}-03$ \\
Adenylate kinase isoenzyme 1 & AK1 & 1.17 & $5.85 \mathrm{E}-03$ \\
ATP synthase mitochondrial F1 & ATPAF1 & 1.26 & $5.86 \mathrm{E}-03$ \\
complex assembly factor 1 & & & \\
Granulins & GRN & 1.34 & $5.82 \mathrm{E}-04$ \\
Beta-hexosaminidase subunit alpha & HEXA & 1.37 & $4.81 \mathrm{E}-04$ \\
Protein FAM162A & FAM162A & 1.38 & $6.68 \mathrm{E}-04$ \\
Tissue alpha-L-fucosidase & FUCA1 & 1.58 & $3.36 \mathrm{E}-03$ \\
Dipeptidyl peptidase 2 & DPP7 & 1.62 & $1.66 \mathrm{E}-03$ \\
Four and a half LIM domains protein 2 & FHL2 & 1.64 & $3.14 \mathrm{E}-03$ \\
Fatty acid-binding protein, heart & FABP3 & 1.70 & $2.36 \mathrm{E}-03$ \\
Alpha-N-acetylglucosaminidase & NAGLU & 1.80 & $9.35 \mathrm{E}-03$ \\
Vacuolar protein sorting-associated & VTA1 & 1.83 & $7.35 \mathrm{E}-03$ \\
protein VTA1 homolog & & & \\
Lysosomal protective protein & CTSA & 1.85 & $3.72 \mathrm{E}-06$ \\
Unconventional myosin-VI & MYO6 & 1.97 & $1.89 \mathrm{E}-03$ \\
Arylsulfatase B & ARSB & 2.43 & $3.38 \mathrm{E}-04$ \\
Acid ceramidase & ASAH1 & 2.57 & $6.39 \mathrm{E}-03$ \\
Mammalian ependymin-related & EPDR1 & 3.50 & $1.09 \mathrm{E}-03$ \\
protein 1 & & & \\
\hline Log fold chan & & & \\
\hline
\end{tabular}

$\log _{2}$ fold change and $p$ values of the proteins highlighted in the volcano plot shown in Fig. 2

$n=8$, middle diagram), but not after $72 \mathrm{~h}$ (Fig. $5 \mathrm{~b}$, lower diagram), the effect of C2-CER on viability reached statistical significance. These results are in line with the confluency measurements (Fig. 5a), but the basal release of LDH is possibly superimposing the effect of C2-CER. Our studies on GCs using exogenously applied soluble C2-CER support the previous findings that ceramide induces a form of necrotic cell death in GCs.

\section{Necrosulfonamid but not the apoptosis inhibitor ZVAD- fmk counteracted the effect of C2-CER}

To analyse the types of cell death occurring in culture, we stimulated GCs with C2-CER $(50 \mu \mathrm{M})$ alone or in combination with NSA $(20 \mu \mathrm{M})$ or zVAD-fmk $(20 \mu \mathrm{M})$ for $72 \mathrm{~h}$, starting on day 1 or 2 of culture. The addition of NSA had a positive effect on confluency $(121.3 \pm 8.2 \%, n=6$, Fig. 5 c, upper diagram). Co-treatment with zVAD-fmk had no effect on confluency of C2-CER-treated GCs $(102.4 \pm 1.9 \%$, $n=5$, Fig. 5 c, middle diagram). Evaluation of cell numbers after a $72 \mathrm{~h}$ stimulation likewise showed a significant positive effect of NSA $\left(8.50 \times 10^{4} \pm 0.53 \times 10^{4}\right.$ cells, $\left.n=12\right)$ and no effect of zVAD-fmk $\left(5.75 \times 10^{4} \pm 0.80 \times 10^{4}\right.$ cells, $\left.n=8\right)$ 


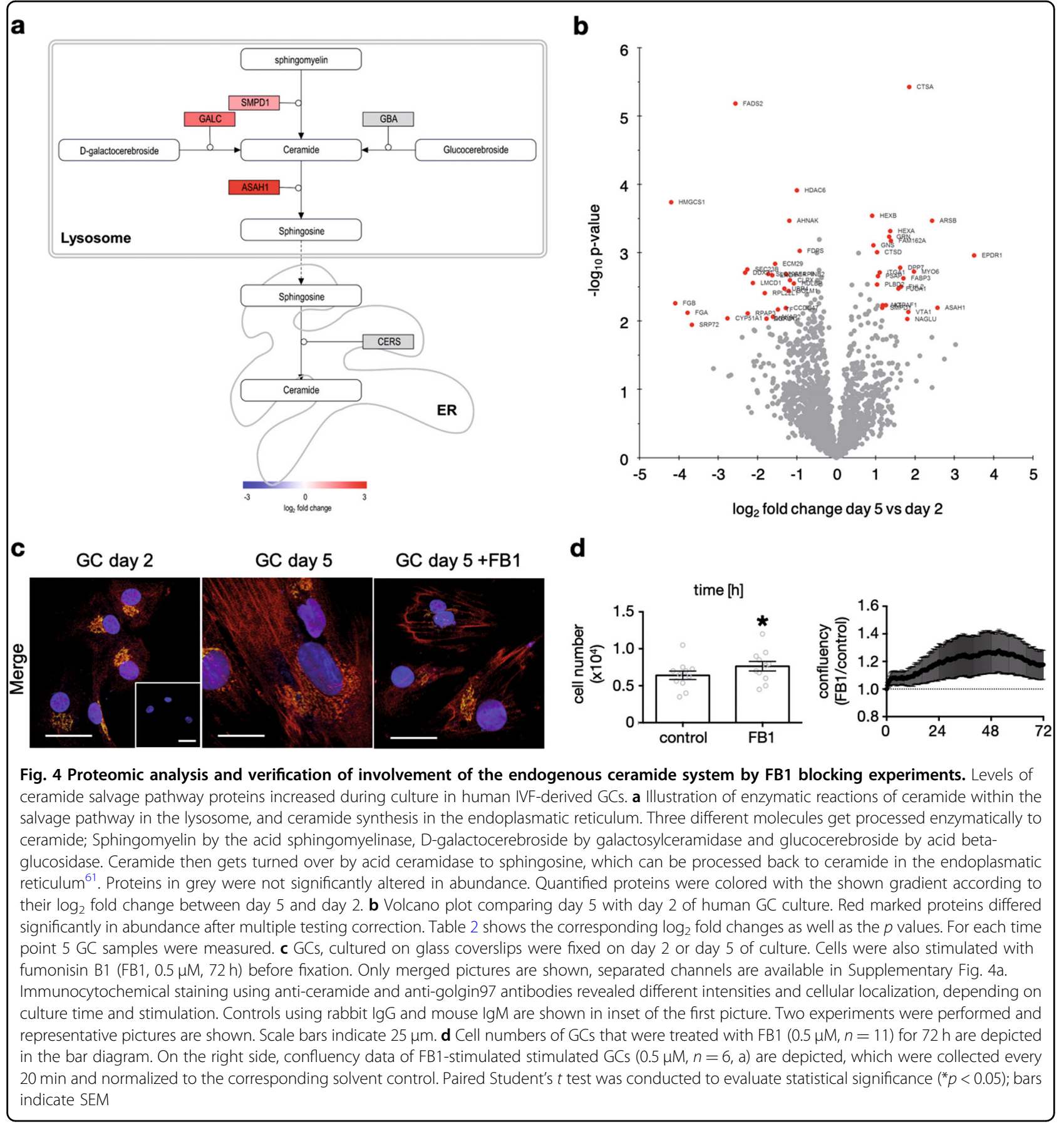

in comparison to C2-CER-only treatment $\left(6.14 \times 10^{4} \pm\right.$ $0.42 \times 10^{4}$ cells, $n=11$, Fig. 5 c, bar diagram).

As MLKL phosphorylation and oligomerization are the known terminal steps of necroptosis, we examined by western blot analyses whether the addition of C2-CER (50 $\mu \mathrm{M}, 72 \mathrm{~h}$ starting of day 1 or 2) is able to increase pMLKL (T357/S358). We detected bands corresponding to the monomeric and the oligomeric form of PMLKL in the C2-CER treated and the solvent group, yet without a significant difference ( $n=5$, Supplementary Fig. 3b). A high degree of variability became evident. Co-treatment of C2-CER $(50 \mu \mathrm{M})$ and NSA $(20 \mu \mathrm{M})$ yielded a significant reduction of pMLKL(T357/S358) levels, when compared to the group solely treated with C2-CER ( $n=5$, Supplementary Fig. 3c).

We also cultured GCs in the presence of NSA $(20 \mu \mathrm{M}$, Supplementary Fig. 3a) for $72 \mathrm{~h}$ between day 2 and 5 and performed immunocytochemistry. As expected, we found 
a
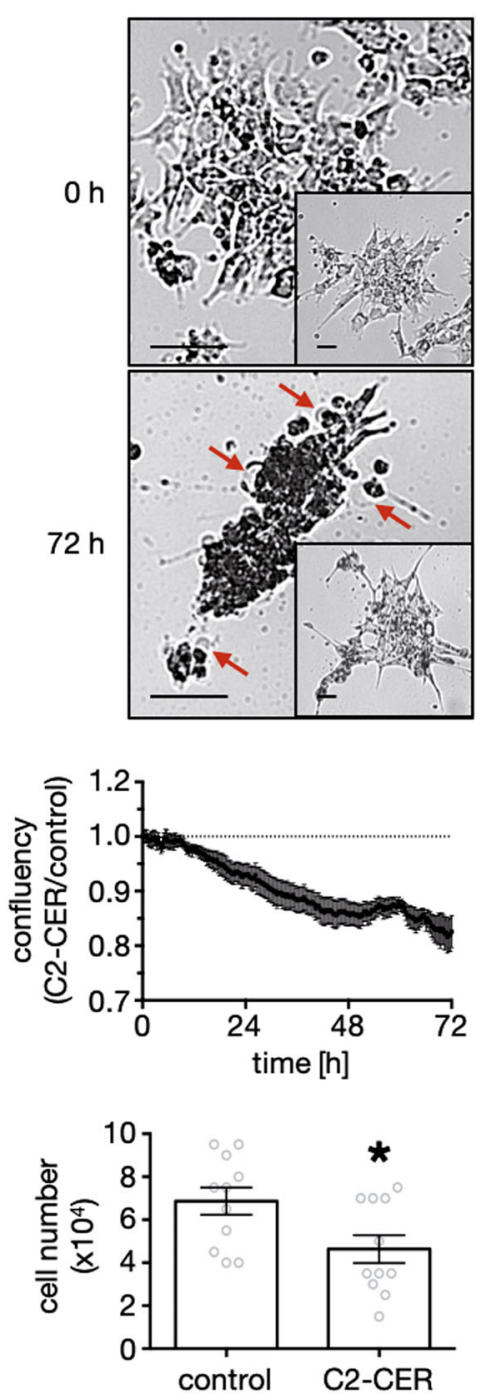

b

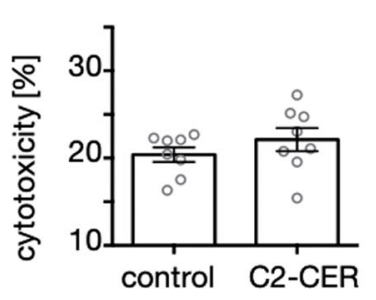

GC day 2-3

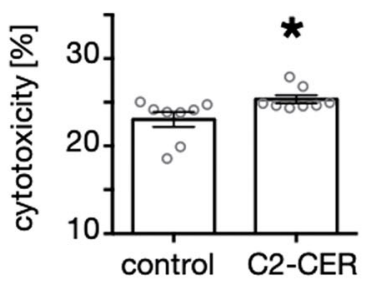

GC day 2-4

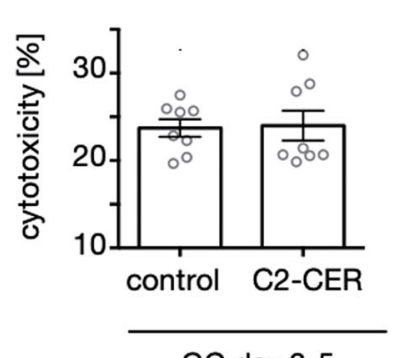

GC day $2-5$
C
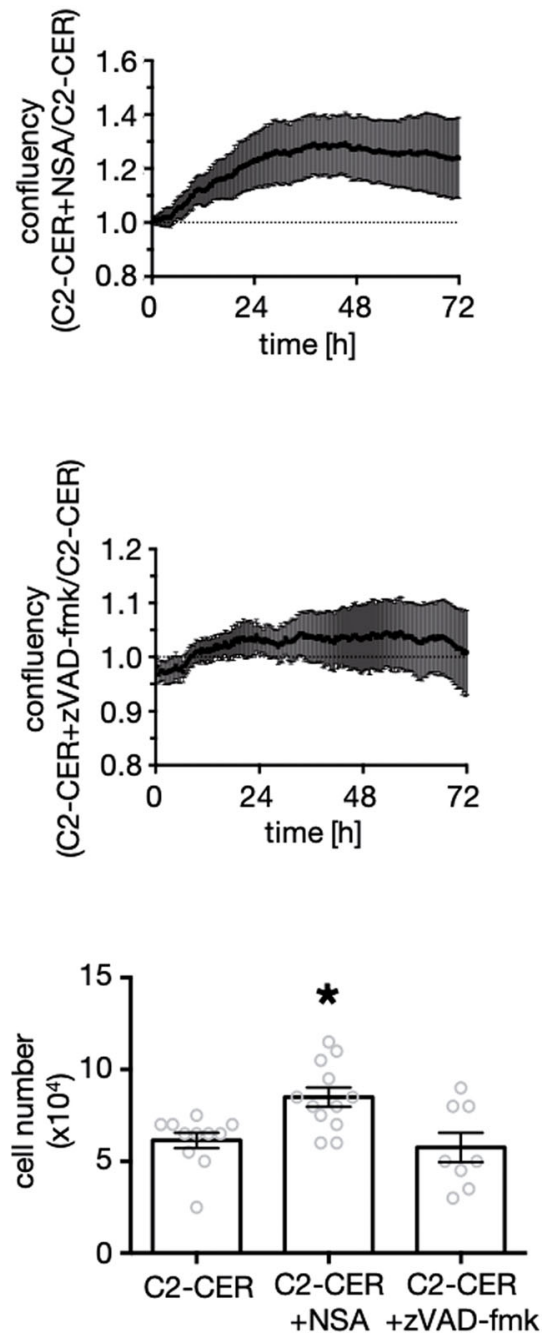

Fig. 5 Exogenous administration of an ceramide derivative induced a form of necrotic cell death. a Representative pictures of C2-CERstimulated GCs $(50 \mu \mathrm{M})$ at the beginning $(0 \mathrm{~h})$ and in the end $(72 \mathrm{~h})$ of the stimulation are shown. Morphological signs of necrotic cell death e.g. ballooning are indicated by red arrows. Controls, which show less cell death are depicted within the inset, appropriate to the time points. Confluency data of C2-CER (50 $\mu \mathrm{M}, n=9)$ stimulated GCs was collected every $20 \mathrm{~min}$ and normalized to the corresponding solvent control. Cell numbers of GCs, which were treated with C2-CER (50 $\mu \mathrm{M}, n=11)$ for $72 \mathrm{~h}$ are depicted in the bar diagrams. b Colorimetric LDH Assay of GCs stimulated with C2-CER $(50 \mu \mathrm{M})$ or solvent control between day 2 and 3 (upper diagram), day 2 and 4 (middle diagram) and day 2 and 5 (lower diagram). Cytotoxicity was evaluated according to the manufacturer's recommendations. Each data point represents one sample $(n=8)$. Confluency data of GCs stimulated with C2-CER $(50 \mu \mathrm{M}$, control) alone or in presence of NSA $(20 \mu \mathrm{M}, n=6$, a) or ZVAD-fmk $(20 \mu \mathrm{M}, n=5$, b) were collected every 20 min for $72 \mathrm{~h}$ and normalized to the control group. c Cell numbers after $72 \mathrm{~h}$ of stimulation for the treatments C2-CER ( $50 \mu \mathrm{M}, n=11), \mathrm{C} 2-\mathrm{CER}+\mathrm{NSA}(50 \mu \mathrm{M}, 20 \mu \mathrm{M}$, $n=12)$ and C2-CER + zVAD-fmk (50 $\mu \mathrm{M}, 20 \mu \mathrm{M}, n=8)$ are depicted. $(\mathbf{a}, \mathbf{b})$ paired Student's $t$-test was conducted to evaluate statistical significance $\left({ }^{*} p<0.05\right)$. (c) statistical significance was evaluated by testing against the control group using Kruskall-Wallis multiple comparison test $\left({ }^{*} p<0.05\right)$. $(\mathbf{a}-\mathbf{c})$ bars indicate SEM

increased ceramide staining over culture time, which unexpectedly was reduced upon addition of NSA (Supplementary Fig. 3a). To explore possible off-target effects, we conducted the same experiment using a blocker, which is known to have less off-target effects and acts as an upstream inhibitor of necroptosis by targeting RIP1, namely necrostatin $1 \mathrm{~s}$ (Nec-1s, $20 \mu \mathrm{M}$, Supplementary Fig. $4 \mathrm{~b})^{47}$. This experiment yielded comparable results supporting the hypothesis that ceramide generation and necroptosis are interlinked pathways. 


\section{Discussion}

Necrosis and necroptosis are generally linked to harmful or pathological processes ${ }^{48}$. Our cellular studies combined with the analysis of luteal samples indicate that necroptosis occurs in the CL of nonhuman primates and humans, as a physiological process linked to luteolysis, which is possibly fuelled by ceramide actions.

To date, very little is known about a physiological role of necro(pto)sis ${ }^{49}$. For example, during development of $C$. elegans, the linker cell helps to shape gonads in male worms and dies afterwards, lacking apoptosis marker but exhibiting morphological signs of necrosis ${ }^{50}$. In nonhuman primates, a functional study using ovarian follicle culture indicated involvement of necroptosis in follicular death $^{27}$. A cell culture study in human GCs revealed spontaneously occurring necroptosis, which was further stimulated upon addition of a peptide (ARP) corresponding to a splice variant of acetylcholineesterase ${ }^{26}$. We now document phosphorylation of MLKL at T357/S358 in large luteal cells of regressing $\mathrm{CL}$ in macaques. Necroptotic cells were likewise identified in other primate species, including marmosets and humans, though the exact stages of the CL were not known. Furthermore, we assessed necroptotic cell death of GCs in a time course experiment, using pRIP1(S166), pRIP3(S277), pMLKL (T357/S358) and their unphosphorylated counterparts. We found necroptosis to occur over culture time. Due to pMLKL oligomerization at day 3 and 5 of culture we concluded that execution of necroptosis takes place on and after day 3 of culture. These results were supported by increasing $\mathrm{LDH}$ concentrations in culture medium over time.

As GCs differentiate in culture and also die over time, we reasoned that the culture of IVF-derived GCs is an apt model to explore possible mechanisms of necroptotic cell death related to the events in the CL. Results of a proteomic analysis of GCs allowed us to identify the ceramide salvage pathway. Many contributing enzymes were consistently upregulated, leading to the hypothesis that localization and/or quantity of sphingolipid species could change $^{20,51}$. Comparison between the proteomic and the transcriptomic data indicated a high degree of similarity in protein and gene expression patterns between the two datasets, especially components involved in the ceramide salvage pathway, which indicated its physiological relevance. As both, GC necroptosis and elevated expression of ceramide salvage proteins take place during GC culture, we explored whether these pathways may be interlinked.

The salvage pathway may result in accumulation of two principle metabolites, ceramide and sphingosine ${ }^{20}$. Ceramide accumulation during necroptosis was shown before and was linked to de novo lipogenesis ${ }^{52}$. However, proteins associated with the synthesis of fatty acids were not changed in cultured GCs (ATP citrate lyase, ACLY; fatty acid synthase, FASN; fatty acid elongase1 and 5, ELOVL1 and 5) or were even strongly downregulated (acetyl-CoA carboxylase $\alpha$, ACACA, $\log _{2} \mathrm{FC}=-1.74$ ). Hence, we concluded that ceramide stems from the salvage pathway. An immunocytochemical approach endorsed the LC-MS/MS data, and ceramide levels increased with culture time. Addition of the ceramide synthase blocker $\mathrm{FB}^{31,32,53}$ reduced ceramide staining. FB1 also improved cell viability. Taken together, these results lead us to conclude that ceramide accumulation has a negative effect on GC viability by inducing cell death.

We also challenged GCs with a soluble, cell permeable ceramide analogue, C2-CER. It decreased cell viability. The change in confluency became evident during the first $48 \mathrm{~h}$ of imaging and was only marginally altered afterwards. Likewise, we found slightly but statistically significantly higher LDH levels due to C2-CER treatment albeit only after $48 \mathrm{~h}$, a result which points at a necrotic form of cell death. Typical morphological signs of necro (pto)sis, including ballooning and cell burst, were evident in the C2-CER treated groups ${ }^{54}$.

The results obtained in GCs are in line with previous data $^{11,55,56}$, which indicated that ceramide is associated with apoptosis or necroptosis in non-primate GCs. To further examine the forms of cell death in GCs, we tested the actions of NSA and zVAD-fmk. NSA is a known inhibitor of MLKL that covalently modifies Cys88, and subsequently blocks MLKL oligomerization and execution of cell death ${ }^{57}$. This blocker had an positive effect on confluency and cell number, which was lowered by $\mathrm{C} 2$ CER, whereas zVAD-fmk lacked such actions. While all these results point to the ability of C2-CER to induce necroptosis in GCs, Western Blot studies indicated that the known necroptosis executioner protein, i.e., phosphorylated MLKL, was not further elevated upon treatment. However, the addition of NSA reduced MLKL phosphorylation and lowered oligomerization of MLKL compared to C2-CER treated groups ${ }^{12}$. Human GCs are patient-derived primary cells and exhibit a large degree of variability ${ }^{26}$. It is possible that this fact contributes to the inability to decide from this type of experiment whether or to what degree the ongoing necroptotic events in GCs may be further enhanced by exogenous C2-CER.

Previous research showed that ceramide accumulation occurred downstream of RIP1 activation in TNF $\alpha$ induced necroptosis ${ }^{58}$. However, there is also a link between ceramide production, general perturbation in cell metabolism and cell death ${ }^{59}$. We found that the addition of inhibitors targeting two steps in necroptosis, NSA and $\mathrm{Nec}-1 \mathrm{~s}$, both reduced ceramide staining. Clearly, while off-target actions of the drugs can not be ruled out, this may also indicate that ceramide production is complexly regulated in GCs and linked to necroptotic cell death. 
In summary, results obtained in a cellular model and in vivo-developed CL from humans and nonhuman primates, indicate that necroptotic cell death contributes to the demise of the CL. This implicates necroptosis as a physiologically occurring event in the ovary. We suggest that the ceramide salvage pathway has a role in CL regression. Increased endogenous ceramide production is proposed as an inducer of this form of necrotic cell death in GCs. The cellular results also raise the possibility that the primate CL could be rescued by pharmacological inhibition of necroptosis or by modulation of ceramide metabolism. The applicability of such an approach in luteal-phase dysfunctions remains to be tested ${ }^{60}$.

\section{Materials and methods}

\section{Culture and treatment of human IVF-derived GCs}

The use of human IVF-derived GCs was approved by the ethics committee of the Ludwig-Maximilians University in Munich and each patient approved the use of cells. GCs were isolated from follicular fluid (FF), as previously described ${ }^{28-30}$. In brief, pooled FF from at least two patients was filtered $(40 \mu \mathrm{m}$ EASYstrainer, Grainer Bio-One, Kremsmünster, A), and the residuum was washed and backwashed with medium (1:1 DMEM/F12, Thermo Fisher Scientific, Waltham, MA, USA). Afterwards, cells were singularized through a $0.9 \times 40 \mathrm{~mm}$ syringe (B.Braun Melsungen, Melsungen, GER) and centrifuged at $800 \mathrm{~g}$ for $3 \mathrm{~min}$. Next, cell pellet was resuspended in DMEM/F12 medium, supplemented with fetal calf serum (FCS, $10 \%)$, penicillin $(100 \mathrm{U} / \mathrm{ml})$ and streptomycin $(100 \mu \mathrm{g} / \mathrm{ml})$, and counted using Neubauer chamber method. A total of $10^{5}$ cells were seeded per 35 $\mathrm{mm}^{2}$ plate (Sarstedt AG \& Co. KG, Nümbrecht, GER) and cultivated at $37^{\circ} \mathrm{C}$ and $5 \% \mathrm{CO}_{2}$. After $24 \mathrm{~h}$ of cultivation (day 1), non-adherent cells were removed by washing. For immunocytochemistry, cells were trypsinized at day 1 of culture and seeded onto glass coverslips in a 24 well plate $\left(10^{4}\right.$ cells/well, Sarstedt AG \& Co. KG, Nümbrecht, GER). All experiments were carried out using cell culture medium.

For live cell experiments, GCs were stimulated with a synthetic, soluble and cell permeable ceramide analogue alone (C2-ceramide, $50 \mu \mathrm{M}$, Enzo Life Sciences Inc., Farmingdale NY, USA) or in combination with either the MLKL inhibitor necrosulfonamid (NSA, $20 \mu \mathrm{M}$, Cat. No. $5025)$ or the pan-caspase (apoptosis) inhibitor z-VADfmk (20 $\mu \mathrm{M}$, Cat. No. 2163). Both inhibitors were ordered from Tocris Bioscience (Bristol, UK). Further, a widely used ceramide synthase inhibitor fumonisin B1 (FB1, $0.5 \mu \mathrm{M}$, Enzo Life Sciences Inc., Farmingdale NY, USA) was administrated to block endogenous ceramide generation $^{31,32}$. All experiments were carried out for at least six times if not described otherwise.

\section{Confluency measurement and cell counting}

Confluency of GCs between day 1 and day 5 of culture was measured for a period of $72 \mathrm{~h}$, as described before ${ }^{26}$. For cell counting experiments, cells were rinsed with PBS post treatment, trypsinized and counted using the Neubauer chamber method. All experiments were carried out for at least eight times if not described otherwise.

\section{Immunohistochemistry}

We immunohistochemically stained pMLKL(T357/ S358) using the specific antibody (ab187091, Abcam, Cambridge, UK) to identify necroptosis in tissue sections of macaque, marmoset (Callithrix jacchus) and human ovaries. Samples from macaques were consecutive sections of those described previously ${ }^{33}$. Additional samples were provided by the Oregon National Primate Research Center, Oregon Health \& Science University (Beaverton, OR, USA) collected during days 3-5 (early), days 7-8 (mid) and days 14-16 (late) after the midcycle LH surge in a previous study ${ }^{34}$. Marmoset samples are from the German Primate Center (Göttingen, GER) and were taken from the histological sample archive of the Platform Degenerative Diseases. The samples were fixed in Bouin's solution and embedded in paraffin. All immunohistochemistry procedures were conducted as previously described $^{27}$. In brief, sections were deparaffinized, antigens were retrieved using the HIER method, and endogenous peroxidase was blocked with $\mathrm{H}_{2} \mathrm{O}_{2}$ (3 in $10 \%$ methanol). Further, unspecific binding was prevented by incubation with $10 \%$ goat serum in PBS. Positive antibody staining resulted from complexing of antigen bound primary antibody with biotinylated secondary antibody and avidin (ABC kit). Pre-absorption of anti-pMLKL(T357/ S358) antibody using the respective peptide (ab206929, Abcam, Cambridge, UK) was done as previously described $^{27}$. Immunohistochemical staining was carried out on three human CL samples, two marmoset CL samples and three timed series of macaque CL samples.

\section{Immunocytochemistry}

To determine expression and localization of ceramide over culture time, we used a monoclonal anti-ceramide antibody (anti-CER, clone MID15B4, Enzo Life Sciences Inc., Farmingdale, NY, USA) in an immunocytochemical approach. This antibody detects different ceramide species including dihydroceramide, C16- and C24-ceramide ${ }^{35}$. Furthermore, anti-golgin97 antibody (Thermo Fisher Scientific, Waltham, MA, USA) was used to examine ceramide localization. Cells were stimulated at day 2 of culture with $0.5 \mu \mathrm{M}$ FB1, $20 \mu \mathrm{M}$ Necrostatin-1s (Nec-1s, a potent RIP1-kinase inhibitor) or $20 \mu \mathrm{M}$ NSA for $72 \mathrm{~h}$. After 5 days of culture and $72 \mathrm{~h}$ of stimulation, GCs were fixed in a $4 \%$ formaldehyde solution and permeabilized on ice using $0.2 \%$ Triton X-100 in PBS. To block unspecific binding, cells 
were incubated with $5 \%$ goat serum in PBS. Specific immuno-decoration was achieved during $1.5 \mathrm{~h}$ incubation at room temperature. After three $5 \mathrm{~min}$ wash steps with 0.1 \% Triton X-100 in PBS, a fluorophore-antibody conjugate was used to visualize specific antibody binding. For detection of anti-CER binding, Rhodamine conjugated $\mathrm{F}$ $\left(a b^{\prime}\right)_{2}$ fragment goat anti-mouse IgM (Jackson ImmunoResearch Inc., West Grove, PA, USA) was used (kindly provided by D. Dormann laboratory (Ludwig-Maximilians University, Department of Cell Biology, Munich, GER). Anti-golgin97 antibody was detected using Alexa488 conjugated donkey anti-mouse IgG $(\mathrm{H}+\mathrm{L}$ ) (Thermo Fisher Scientific, Waltham MA, USA). As controls, mouse serum IgG (Sigma-Aldrich, St. Louis, MI, USA) and IgM (Thermo Fisher Scientific, Waltham MA, USA) were used. Examination by confocal microscopy was conducted at the bioimaging core facility of the Biomedical Center (Ludwig Maximilians University, Munich, GER) using an inverted Leica SP8 microscope, equipped with lasers for 405, 488, 552 and $638 \mathrm{~nm}$ excitation. Images were acquired with a HC PL APO $63 \times / 1.40$ oil objective. Fluorescence was recorded with hybrid photo detectors (HyDs), and DAPI with a conventional photomultiplier tube. All experiments were carried out for at least three times.

\section{LDH assay}

Pierce LDH Cytotoxicity Assay Kit (PI, Thermo Fisher Scientific, Waltham, USA) was carried out as recommended by the manufacturer and described previously ${ }^{26}$. In brief, GCs were isolated and pools of at least 2 patients were cultured for $24 \mathrm{~h}$. At day 1 of culture the cells were trypsinized and seeded at $10^{4}$ cells/well in 96-well plates. At day 2 of culture growth medium was changed and cells were treated with C2-CER $(50 \mu \mathrm{M})$ or solvent control. After 1,2 or 3 days of stimulation LDH levels were measured using a microplate reader (FLUOStar Optima, BMG Labtech, Ortenberg, GER). To calculate cytotoxicity a serum control, serum free control and controls treated with lysis buffer before measurement ( $\max \mathrm{LDH})$ were included.

\section{Protein isolation and western blot}

Protein isolation and Western Blot were conducted as previously described ${ }^{26,27}$. In brief, GCs were lysed after 1 to 5 days of culture using RIPA buffer containing protease and phosphatase inhibitors (PI, Thermo Fisher Scientific, Waltham, USA). A total of $10 \mu \mathrm{g}$ protein per lane was loaded on a $12 \%$ SDS gel and run under constant current $(30 \mathrm{~mA} / \mathrm{gel})$. After blotting (100 $\mathrm{V}, 65 \mathrm{~min}$ ) and blocking with $5 \%$ non-fat dry milk in Tris-buffered saline with Tween 20 (TBS-T, $50 \mathrm{mM}$ Tris$\mathrm{HCl}, 150 \mathrm{mM} \mathrm{NaCl}, 0.1 \%$ Tween 20, pH 7.4), anti-pRIP1 (S166), anti-pRIP3(S227) both from Cell Signaling Technology (Danvers, MA, USA) and anti-pMLKL
(T357/S358) antibodies were administered to decorate these phosphorylated proteins. To visualize specific binding, HRP-conjugated goat anti-rabbit antibody (Jackson ImmunoResearch Inc., West Grove, PA, USA) was used. As loading controls, anti-RIP1, anti-RIP3 (both from Cell Signaling Technology, Danvers, MA, USA), anti-MLKL (ab184718, Abcam, Cambridge, UK) and anti- $\beta$-actin (A5441, Sigma-Aldrich, St. Louis, MI, USA) antibodies were used. Preabsorption of anti-pMLKL was previously published ${ }^{27}$. All experiments were carried out five times if not described otherwise.

\section{Protein mass spectrometry (LC-MS/MS)}

GCs cultured for 2 to 5 days were analyzed using a label-free approach. LC-MS/MS was performed as previously described ${ }^{36}$. In brief, $2.5 \mu \mathrm{g}$ total proteins were reduced using DTT, alkylated and digested at $37^{\circ} \mathrm{C}$ with LysC for $4 \mathrm{~h}$ followed by trypsin overnight. LC-MS/MS was performed with an Ultimate 3000 RSLC chromatography system coupled to a $5600^{+}$mass spectrometer.

Raw files were processed using MaxQuant (version: 1.5.8.3) and default settings with the following exceptions: (a) label-free quantification was set to on; (b) "LFQ minimum ratio count" was set to 1 ; and (c) the "match between runs" feature was turned on. As databases, the human Swiss-Prot subset (Release 06/2017) and the common contaminants from MaxQuant were used ${ }^{37}$. For protein Identification, the data were searched with a target decoy approach resulting in $\mathrm{a}<1 \%$ False Discovery Rate (FDR). The mass spectrometry data were submitted to the ProteomeXchange Consortium via the PRIDE partner repository (identifier PXD010658). Statistical analysis was done with Perseus (version 1.6.0.7). The samples were first grouped based on their day of cultivation. For pair-wise comparisons, a minimum of 4 values in at least one group were required. The filtered and imputed data were used to calculate $\log _{2}$ fold changes with a two-sided Welch's $t$-test. Multiple Testing correction was performed using the Permutation-based FDR (5\% FDR) which is based on calculation of q-values and provided with Perseus. Proteins with a q-value $<0.05$ and a $\log _{2}$ fold change $>|0.6|$ were considered significantly different in abundance. For the "DAVID Functional Annotation Clustering", proteins were filtered less stringent with a $p$ value $<0.05$ and a $\log _{2}$ fold change $>$ | $\left.0.6\right|^{38,39}$. This list was then analyzed with the DAVID online tool to build annotation based clusters according to the GO terms (molecular function, biological process and cellular component) and the reactome pathway database. Only clusters where at least one annotation component had a corrected $p$ value (Benjamini) $<0.01$ and an enrichment score $>2.5$ were seen as significantly enriched.

Pathway illustrations were done with pathvisio ${ }^{40,41}$. The volcano plot was performed with Microsoft Excel 
(Redmond, USA) using the results from the Welch's $t$-test mentioned above.

\section{Microarray and real-time PCR}

This was a retrospective study assessing mRNA levels of target genes in rhesus macaque $\mathrm{CL}$ samples collected during day 3-5 (early) and day 14-16 (late) after the midcycle LH surge in a previous study ${ }^{42}$. The normalized and $\log$ transformed (base 2) microarray data were downloaded from the NCBI Gene Expression Omnibus repository (https://www.ncbi.nlm.nih.gov/gds) Dataset Series \#GSE10367 ${ }^{42}$.The target genes searched were ARSA, ASAH1, CTSA, GALC, GBA, GLA, GLB1, GM2A, HEXA, HEXB, NEU1, PSAP, SCARB2, and SMPD1. The RNA samples used for microarray analysis were used to synthesize cDNA, as described previously ${ }^{42}$. Real-time PCR was performed using TaqMan Gene Expression Assays (Thermo Fisher Scientific, Waltham, MA, USA) and Applied Biosystems 7900HT Fast Real-time PCR System (Thermo Fisher Scientific, Waltham, MA, USA), as previously described ${ }^{43}$, for selected genes including ASAH1 (Assay ID: Hs00602774_m1), CERS2 (Assay ID: Hs00371958_g1), GBA (Assay ID: Hs00986836_g1), and SMPD1 (Assay ID: Hs003679347_g1). Mitochondrial ribosomal protein S10 (MRPS10) served as the internal control.

\section{Statistical analysis}

Graphs were constructed in Prism 6 running under Mac OS X, whereby statistical analysis of cell counts, LDH Assays, Western Blot and gene expression were done using the same program and two-sided Student's $t$ test. LDH Assay with more than two groups were analysed using Oneway ANOVA with Dunett correction. Cell count experiments with more than two independent groups were analysed using Kruskall-Wallis multiple comparison test. $P$ values $<0.05$ were considered as significant. The microarray transcriptome analysis was performed using the GeneShifter (VizX Labs, Seattle, WA, USA) software and the Affymetrix Expression Console, as described previously $^{42}$.

\section{Acknowledgements}

We thank Kim-Gwendolyn Dietrich and Astrid Tiefenbacher for expert support. Further we thank Idoya Lahortiga and Luk Cox for the allowance to use the graphical content from www.somersault1824.de for Fig. 2. This work was performed in partial fulfilment of the requirements of a Dr. rer. nat. thesis (KB) at LMU. Grant support: Deutsche Forschungsgemeinschaft (DFG) MA1080/19-2, $\mathrm{NIH/OD} \mathrm{P51OD011092.}$

\section{Author details}

${ }^{1}$ Biomedical Center Munich (BMC), Cell Biology, Anatomy III, LudwigMaximilians-University (LMU), Grosshaderner Strasse 9, Planegg 82152, Germany. ${ }^{2}$ Laboratory for Functional Genome Analysis LAFUGA, Gene Center, LMU, Feodor-Lynen Strasse 25, Munich 81375, Germany. ${ }^{3}$ Platform Degenerative Diseases, German Primate Center, Kellnerweg 4, Göttingen 37077, Germany. ${ }^{4}$ A.R.T. Bogenhausen, Prinzregentenstrasse 69, Munich 81675, Germany. ${ }^{5}$ Department Biology II, Division of Neurobiology, LMU,

Grosshaderner Strasse 2, Planegg 82152, Germany. ${ }^{6}$ Division of Reproductive \&
Developmental Sciences, Oregon National Primate Research Center, Oregon Health \& Science University, 505 NW 185th Avenue, Beaverton, Oregon 97006, USA

\section{Conflict of interest}

The authors declare that they have no conflict of interest.

\section{Publisher's note}

Springer Nature remains neutral with regard to jurisdictional claims in published maps and institutional affiliations.

The online version of this article (https://doi.org/10.1038/s41420-019-0149-7) contains supplementary material, which is available to authorized users.

Received: 15 January 2019 Accepted: 22 January 2019

Published online: 11 February 2019

\section{References}

1. Richards, J. S., Russell, D. L., Ochsner, S. \& Espey, L. L. Ovulation: new dimensions and new regulators of the inflammatory-like response. Annu. Rev. Physiol. 64, 69-92 (2002).

2. Green, C., Chatterjee, R., McGarrigle, H. H., Ahmed, F. \& Thomas, N. S. p107 is active in the nucleolus in non-dividing human granulosa lutein cells. J. Mol. Endocrinol. 25, 275-286 (2000).

3. Devoto, L. et al. The human corpus luteum: life cycle and function in natural cycles. Fertil. Steril. 92, 1067-1079 (2009).

4. Shikone, T. et al. Apoptosis of human corpora lutea during cyclic luteal regression and early pregnancy. J. Clin. Endocrinol. Metab. 81, 2376-2380 (1996).

5. Morales, C. et al. Different patterns of structural luteolysis in the human corpus luteum of menstruation. Hum. Reprod. 15, 2119-2128 (2000).

6. Mizushima, $\mathrm{N}$. et al. A protein conjugation system essential for autophagy. Nature 395, 395 (1998).

7. Grzesiak, M., Knapczyk-Stwora, K. \& Słomczyńska, M. Induction of autophagy in the porcine corpus luteum of pregnancy following anti-androgen treatment. Can. J. Physiol. Pharmacol. 67, 933-942 (2016).

8. Bulling, A. et al. Identification of an ovarian voltage-activated $\mathrm{Na}+$-channel type: hints to involvement in luteolysis. Mol. Endocrinol. 14, 1064-1074 (2000).

9. Wu, R., Van der Hoek, K. H., Ryan, N. K., Norman, R. J. \& Robker, R. L. Macrophage contributions to ovarian function. Hum. Reprod. Update 10, 119-133 (2004).

10. Bishop, C. V. et al. Changes in immune cell distribution and their cytokine/ chemokine production during regression of the rhesus macaque corpus luteum. Biol. Reprod. 96, 1210-1220 (2017).

11. Hojo, T. et al. Programmed necrosis - a new mechanism of steroidogenic luteal cell death and elimination during luteolysis in cows. Sci. Rep. 6, 38211 (2016).

12. Huang, D. et al. The MLKL channel in necroptosis is an octamer formed by tetramers in a dyadic process. Mol. Cell Biol. 37, https://doi.org/10.1128/ mcb.00497-16 (2017).

13. Galluzzi, L. et al. Molecular mechanisms of cell death: recommendations of the Nomenclature Committee on Cell Death 2018. Cell Death \& Differ. 25, 486-541 (2018).

14. Linkermann, A. \& Green, D. R. Necroptosis. N. Eng. J. Med. 370, 455-465 (2014).

15. Carlson, J. C., Buhr, M. M. \& Riley, J. C. Plasma membrane changes during corpus luteum regression. Can. J. Physiol. Pharmacol. 67, 957-961 (1989).

16. Pru, J. K., Hendry, I. R., Davis, J. S. \& Rueda, B. R. Soluble Fas ligand activates the sphingomyelin pathway and induces apoptosis in luteal steroidogenic cells independently of stress-activated p38MAPK. Endocrinology 143, 4350-4357 (2002).

17. Kim, M. Y., Linardic, C., Obeid, L. \& Hannun, Y. Identification of sphingomyelin turnover as an effector mechanism for the action of tumor necrosis factor alpha and gamma-interferon. Specific role in cell differentiation. J. Biol. Chem. 266, 484-489 (1991).

18. Goldkorn, T. et al. $\mathrm{H} 2 \mathrm{O} 2$ acts on cellular membranes to generate ceramide signaling and initiate apoptosis in tracheobronchial epithelial cells. J. Cell. Sci. 111(Pt 21), 3209-3220 (1998). 
19. Menaldino, D. S. et al. Sphingoid bases and de novo ceramide synthesis: enzymes involved, pharmacology and mechanisms of action. Pharmacol. Res. 47, 373-381 (2003).

20. Kitatani, K., Idkowiak-Baldys, J. \& Hannun, Y. A. The sphingolipid salvage pathway in ceramide metabolism and signaling. Cell Signal. 20, 1010-1018 (2008).

21. Smith, E. R. \& Merrill, A. H. Jr. Differential roles of de novo sphingolipid biosynthesis and turnover in the "burst" of free sphingosine and sphinganine, and their 1-phosphates and $\mathrm{N}$-acyl-derivatives, that occurs upon changing the medium of cells in culture. J. Biol. Chem. 270, 18749-18758 (1995)

22. Ogretmen, B. et al. Biochemical mechanisms of the generation of endogenous long chain ceramide in response to exogenous short chain ceramide in the A549 human lung adenocarcinoma cell line. Role for endogenous ceramide in mediating the action of exogenous ceramide. J. Biol. Chem. 277, 12960-12969 (2002).

23. Takeda, S., Mitsutake, S., Tsuji, K. \& Igarashi, Y. Apoptosis occurs via the ceramide recycling pathway in human $\mathrm{HaCaT}$ keratinocytes. J. Biochem. 139, 255-262 (2006).

24. Mizumura, K. et al. Sphingolipid regulation of lung epithelial cell mitophagy and necroptosis during cigarette smoke exposure. FASEB J.: Off. Publ. Fed. Am Soc. Exp. Biol. 32, 1880-1890 (2018).

25. Zhang, $X$. et al. Ceramide nanoliposomes as a MLKL-dependent, necroptosisinducing, chemotherapeutic reagent in ovarian cancer. Mol. Cancer Ther. 17, 50-59 (2018).

26. Blohberger, J. et al. Readthrough acetylcholinesterase (AChE-R) and regulated necrosis: pharmacological targets for the regulation of ovarian functions? Cell Death Dis. 6, e1685 (2015).

27. Du, Y., Bagnjuk, K., Lawson, M. S., Xu, J. \& Mayerhofer, A. Acetylcholine and necroptosis are players in follicular development in primates. Sci. Rep. 8, 6166 (2018).

28. Mayerhofer, A. et al. Functional dopamine-1 receptors and DARPP-32 are expressed in human ovary and granulosa luteal cells in vitro1. J. Clin. Endocrinol. Metab. 84, 257-264 (1999).

29. Mayerhofer, A., Föhr, K. J., Sterzik, K. \& Gratzl, M. Carbachol increases intracellular free calcium concentrations in human granulosa-lutein cells. J. Endocrinol. 135, 153-159 (1992).

30. Mayerhofer, A., Sterzik, K., Link, H., Wiemann, M. \& Gratzl, M. Effect of oxytocin on free intracellular Ca2 + levels and progesterone release by human granulosa-lutein cells. J. Clin. Endocrinol. \& Metab. 77, 1209-1214 (1993).

31. Wang, E., Norred, W. P., Bacon, C. W., Riley, R. T. \& Merrill, A. H. Inhibition of sphingolipid biosynthesis by fumonisins. Implications for diseases associated with Fusarium moniliforme. J. Biol. Chem. 266, 14486-14490 (1991).

32. Kim, S. H., Singh, M. P., Sharma, C. \& Kang, S. C. Fumonisin B1 actuates oxidative stress-associated colonic damage via apoptosis and autophagy activation in murine model. J. Biochem. Mol. Toxicol. e22161 (2018). https://doi.org/10.1002/jbt.22161. Epub ahead of print.

33. Kunz, L. et al. Ca2 + -activated, large conductance K+ channel in the ovary: identification, characterization, and functional involvement in steroidogenesis. J. Clin. Endocrinol. Metab. 87, 5566-5574 (2002).

34. Xu, F. \& Stouffer, R. L. Existence of the lymphatic system in the primate corpus luteum. Lymphat. Res. Biol. 7, 159-168 (2009).

35. Cowart, L. A., Szulc, Z., Bielawska, A. \& Hannun, Y. A. Structural determinants of sphingolipid recognition by commercially available anti-ceramide antibodies. J. Lipid Res. 43, 2042-2048 (2002).

36. Schmid, N. et al. Characterization of a nonhuman primate model for the study of testicular peritubular cells - comparison with human testicular cells. Mol. Hum. Reprod. https://doi.org/10.1093/molehr/gay025 (2018).

37. Cox, J. \& Mann, M. MaxQuant enables high peptide identification rates, individualized p.p.b.-range mass accuracies and proteome-wide protein quantification. Nat. Biotechnol. 26, 1367-1372 (2008).
38. Huang da, W., Sherman, B. T. \& Lempicki, R. A. Systematic and integrative analysis of large gene lists using DAVID bioinformatics resources. Nat. Protoc. $\mathbf{4}$ 44-57 (2009).

39. Huang da, W., Sherman, B. T. \& Lempicki, R. A. Bioinformatics enrichment tools: paths toward the comprehensive functional analysis of large gene lists. Nucleic Acids Res. 37, 1-13 (2009).

40. van lersel, M. P. et al. Presenting and exploring biological pathways with PathVisio. BMC Bioinforma. 9, 399 (2008).

41. Kutmon, M. et al. PathVisio 3: an extendable pathway analysis toolbox. PLoS Comput. Biol. 11, e1004085 (2015).

42. Bogan, R. L., Murphy, M. J., Stouffer, R. L. \& Hennebold, J. D. Systematic determination of differential gene expression in the primate corpus luteum during the luteal phase of the menstrual cycle. Mol. Endocrinol. 22, 1260-1273 (2008).

43. Xu, J. et al. Anti-Mullerian hormone is produced heterogeneously in primate preantral follicles and is a potential biomarker for follicle growth and oocyte maturation in vitro. J. Assist. Reprod. Genet. 33, 1665-1675 (2016).

44. Chaffin, C. L., Dissen, G. A. \& Stouffer, R. L. Hormonal regulation of steroidogenic enzyme expression in granulosa cells during the peri-ovulatory interval in monkeys. Mol. Hum. Reprod. 6, 11-18 (2000).

45. Zhou, $X$. et al. Prosaposin facilitates sortilin-independent lysosomal trafficking of progranulin. J. Cell Biol. 210, 991-1002 (2015).

46. Cheng, M. H. \& Jansen, R. P. A jack of all trades: the RNA-binding protein vigilin. Wiley Interdiscip. Rev. RNA 8, 1448 (2017).

47. Takahashi, N. et al. Necrostatin-1 analogues: critical issues on the specificity, activity and in vivo use in experimental disease models. Cell death \& Dis. 3 , e437-e437 (2012)

48. Zhou, W. \& Yuan, J. Necroptosis in health and diseases. Semin. Cell Dev. Biol. 35, 14-23 (2014).

49. Grootjans, S., Vanden Berghe, T. \& Vandenabeele, P. Initiation and execution mechanisms of necroptosis: an overview. Cell Death Differ. 24, 1184 (2017).

50. Abraham, M. C., Lu, Y. \& Shaham, S. A morphologically conserved nonapoptotic program promotes linker cell death in Caenorhabditis elegans. Dev. Cell 12, 73-86 (2007).

51. Wang, S. W. et al. Regulation of ceramide generation during macrophage apoptosis by ASMase and de novo synthesis. Biochim. Et. Biophys. Acta (BBA) Mol. Cell Biol. Lipids 1851, 1482-1489 (2015).

52. Parisi, L. R., Li, N. \& Atilla-Gokcumen, G. E. Very long chain fatty acids are functionally involved in necroptosis. Cell Chem. Biol. 24, 1445-1454.e1448 (2017).

53. Domijan, A. M., Zeljezic, D., Milic, M. \& Peraica, M. Fumonisin B(1): oxidative status and DNA damage in rats. Toxicology 232, 163-169 (2007).

54. Vandenabeele, P., Riquet, F. \& Cappe, B. Necroptosis: (last) message in a bubble. Immunity 47, 1-3 (2017)

55. Santana, P. et al. Ceramide mediates tumor necrosis factor effects on P450aromatase activity in cultured granulosa cells. Endocrinology 136, 2345-2348 (1995).

56. Witty, J. P., Bridgham, J. T. \& Johnson, A. L. Induction of apoptotic cell death in hen granulosa cells by ceramide. Endocrinology 137, 5269-5277 (1996).

57. Liao, D. et al. Necrosulfonamide inhibits necroptosis by selectively targeting the mixed lineage kinase domain-like protein. MedChemComm 5, 333-337 (2014).

58. Sawai, H., Ogiso, H. \& Okazaki, T. Differential changes in sphingolipids between TNF-induced necroptosis and apoptosis in U937 cells and necroptosisresistant sublines. Leuk. Res. 39, 964-970 (2015).

59. Sentelle, R. D. et al. Ceramide targets autophagosomes to mitochondria and induces lethal mitophagy. Nat. Chem. Biol. 8, 831-838 (2012).

60. Devoto, L., Kohen, P., Munoz, A. \& Strauss, J. F. 3rd Human corpus luteum physiology and the luteal-phase dysfunction associated with ovarian stimulation. Reprod. Biomed. Online 18(Suppl 2), 19-24 (2009).

61. Fabregat, A. et al. The reactome pathway knowledgebase. Nucleic Acids Res. 46, D649-d655 (2018) 